\title{
Correction to: Brand love and party preference of young political consumers (voters)
}

\section{Saikat Banerjee ${ }^{1} \cdot$ Bibek Ray Chaudhuri $^{1}$}

Published online: 13 October 2021

๑) Springer-Verlag GmbH Germany, part of Springer Nature 2021

\section{Correction to: International Review on Public and Nonprofit Marketing https://doi.org/10.1007/s12208-021-00316-0}

The correct figure 3 should be the below:

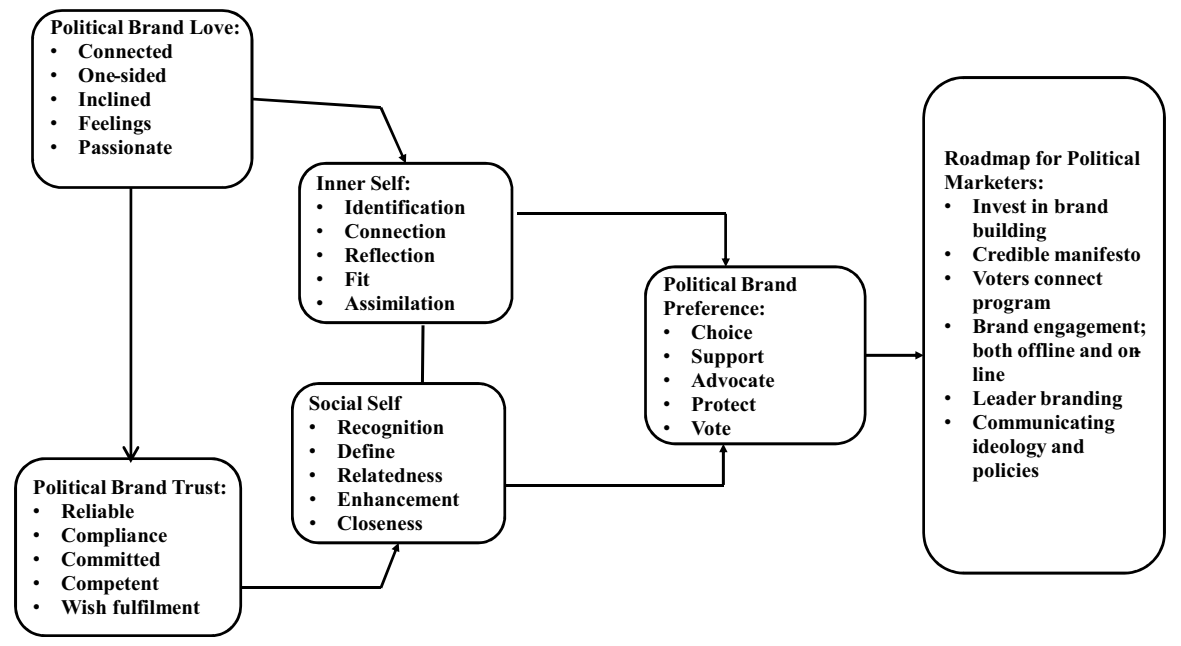

The original article has been corrected.

Publisher's note Springer Nature remains neutral with regard to jurisdictional claims in published maps and institutional affiliations.

The original article can be found online at https://doi.org/10.1007/s12208-021-00316-0.

Saikat Banerjee

saikat@iift.edu; saikat1972@rediffmail.com

Bibek Ray Chaudhuri

brchaudhuri@iift.edu

1 Indian Institute of Foreign Trade (IIFT-Deemed University Under Ministry of Commerce \& Industry, GOI), Madurdaha, Chowbaga Road, Anandapur Road700 107, 1583 Kolkata, India 